\title{
ARTICLE
}

\section{The psychodynamics of psychosis ${ }^{\dagger}$}

\author{
Brian Martindale \& Alison Summers
}

\begin{abstract}
Brian Martindale has worked as a consultant psychiatrist in an early intervention in psychosis service (Northumberland, Tyne and Wear), a consultant psychiatrist in psychotherapy and a World Psychiatric Association Western European Zone representative for psychiatry. He is currently Chair of the International Society for Psychological and Social Approaches to Psychosis (ISPS) and Honorary President of the European Federation for Psychoanalytic

Psychotherapy in the Public Sector. Alison Summers is a consultant psychiatrist working in both an early intervention in psychosis service and psychotherapy in Lancashire. She is also a volunteer psychotherapist with the charity Freedom from Torture and Deputy Chair of ISPS UK. Correspondence Dr Alison Summers, Early Intervention Service, Euxton Lodge, 16 Euxton Lane, Chorley PR7 1PS, UK. Email: Alison. summers@lancashirecare.nhs.uk
\end{abstract}

${ }^{\dagger}$ In the next issue of Advances, Martindale \& Summers will consider how psychodynamic understanding can contribute to a comprehensive formulation to assist recovery.

\section{SUMMARY}

This article outlines common psychodynamics in psychosis. We consider psychosis as a response to unbearable aspects of reality and illustrate how psychodynamic concepts of psychological defence can be used as a framework for understanding this. We also present a psychodynamic approach to understanding the development of psychosis, using the stress-vulnerability model, and discuss interpersonal dynamics in psychosis, particularly their relevance to therapeutic relationships and to interactions between patients and their families. The perspectives presented are intended to complement and enrich other frameworks rather than compete with them.
\end{abstract}

\section{DECLARATION OF INTEREST}

None.

The National Institute for Health and Clinical Excellence (NICE) schizophrenia guideline (2009) recommends that healthcare professionals may consider using psychoanalytic and psychodynamic principles to help them understand patients' experiences and interpersonal relationships. This is the first of a brief series of articles considering how NICE's recommendation might be put into practice, outlining common psychodynamics in psychosis. These articles will draw attention to interpersonal features in psychosis, including those involving families and staff, and will discuss supportive psychodynamic psychotherapy for psychosis. The perspectives presented are intended to complement and enrich other frameworks rather than compete with them. The primary aim of these articles is to assist practitioners in understanding their patients and their needs.

\section{Psychosis as the creation of a "new reality' \\ '... human kind cannot bear very much reality' (Eliot 1935)}

Psychosis is commonly described as a mental state in which there is an altered relation to reality. Usually, reality is taken to mean external reality. However, in psychodynamic approaches to all mental phenomena there is emphasis not only on impressions of external reality but also on changes in processing of psychic or internal emotional reality. These changes help the mind create a more acceptable view of itself and its intersubjective reality, and are mostly in broad accordance with the views of others (these are the defence mechanisms of the non-psychotic part of the personality). Sometimes, however, the mind creates a new 'reality' that is more acceptable to it but which is outside the sphere of 'common sense' (this is the functioning of a psychotic part of the personality).

\section{Different aspects of reality}

A core task of the non-psychotic adult mind is to integrate different aspects of reality, to tolerate conflict between them, to make compromises and to find ways of managing these multiple realities, often at the same time. Some of the different aspects of reality to be integrated are outlined in Box 1 . These are intended as examples and illustrations, not as a comprehensive list or classification.

\section{Dispensing with 'realities'}

In the psychodynamic approach to psychosis, attention is paid to clarifying experiences of reality that the person has found unmanageable and

\section{B0X 1 Different aspects of reality}

\section{External realities}

- How the external world functions (e.g. a day being finite in time, or there being only so much money in one's bank account)

- Events and circumstances (e.g. that one's much loved sister is leaving home, or that people are interacting with each other with small talk or with specific goals)

Internal realities

- Our bodies (e.g. demands on the mind of hunger, sexual drives, illness, ageing)

- Our brain biology (e.g. capacities for learning and thinking, functioning in states of stress)

- The relationship between our minds and the external world (e.g. that words are mental products, representations and not 'things' in themselves, that self and non-self are separate)

- The reality of particular features of our individual personality

- Having a conscience/superego with values, expectations and judgements

- Feelings, thoughts and memories that can sometimes create major discomfort (e.g. shame, humiliation, feelings consequent on loss, longing) 
which have, through the psychosis, been dispensed with or altered, rather than contained, 'digested' and integrated as in non-psychotic states. Once the anxieties, disintegration and emotional pain underlying the psychosis are understood, the psychosis may be seen to have a self-preservative and even a developmental function, as in the case of $\mathrm{D}$ (see next page).

The following fictitious case vignettes contain both indications of the 'reality' dispensed with and the new reality contained in the psychotic phenomena. The changes experienced may be quite narrow and closely related to the aspect of reality which has been too hard to bear, or they may radiate much more widely.

\section{Case vignettes}

\section{External realities}

A had been jilted by his girlfriend and had been feeling painfully inadequate. As he became psychotic, he believed he and a famous singer were regularly making love, even though he was in the UK and the singer in the USA (dispensing with geographical and physical realities).

\section{The reality of our bodies}

$\mathrm{B}$, after several hip replacements and a coronary bypass, continued to go on activity holidays for younger people. He killed himself at the onset of further signs of ageing.

\section{The reality of brain biology}

$\mathrm{C}$, a $\mathrm{PhD}$ student, feels different in ways he cannot explain. The world seems one step removed, his head is full of random thoughts that he cannot control, and he cannot manage his university work. He cannot accept that his brain may not be functioning normally and starts to believe an extraterrestrial power has chosen his mind for use as a cosmic experiment because of his particular intelligence. His earlier distress, fear and confusion are now relieved.

\section{The reality of aspects of self}

D grew up in a culture where it was the norm to attack if threatened or slighted and had been proud of his 'macho' behaviour, which had gained him kudos. His symptoms developed after his first important girlfriend threatened to abandon him if he was violent again. D started to hear voices urging him to do harm to others, and he began to live in fear that others were constantly intending to attack him. The now dangerous aspects of himself are made safer by becoming 'not self': $D$ has unconsciously projected these aspects onto others (including the voice people).

\section{The reality of a conscience}

$\mathrm{E}$ had a row with her long-term partner, went abroad and 'slept around'. On return, she was 'disconnected' from this recent history but complained that she had started to hear voices accusing her of being a 'slut'. She wanted medication to relieve her from the voices.

\section{The reality of unbearable thoughts, feelings} and memories

F, a traumatised woman with a long history of sexual abuse as a young child, speaks about this in a superficial, unemotional manner. At the same time, she can only consume drink through a straw and cannot readily shower as she 'sees' muck coming out of the shower onto her (the memories have lost their mental quality).

$\mathrm{G}$ is manifestly psychotic and violent on Tuesday, but on Wednesday states that he has been fine for many weeks, with complete disconnection from any awareness of the previous day. However, he believes that the police are about to arrive to arrest him and that he is the victim of mistaken identity.

$\mathrm{H}$ is referred after 4 weeks in a hostel in which he seems very apathetic, shunning any communication with others. He has a long history of psychosis and the first impression is that he primarily has negative symptoms of schizophrenia. However, contact is made with his mother with whom he was previously living. She informs staff that while living with her, he was often argumentative and broke her arm in an outburst on the day he left.

\section{Ways of altering reality (psychotic defences)}

Psychodynamic theory also proposes ways of thinking about psychological processes by which reality may be dispensed with, as shown by the examples. These processes, or defence mechanisms, are everyday human phenomena, not restricted to those who would be classified by psychiatrists as psychotic. To some degree we all use these defence mechanisms at times. None of the processes occur in complete isolation from one another. They are unconscious but may give rise to conscious thoughts, feelings and fantasies.

\section{Denial}

Denial of 'common sense' and of culturally and socially accepted meaning of reality is the central psychological defence in psychosis and is a component of all the above examples. Denial of internal reality (integration of thoughts, feelings and judgements) may take the form of not acknowledging aspects of oneself, for example sexuality, aggressive impulses, need for food, or of denying the existence of too harsh and punitive a conscience (as in the case of $\mathrm{E}$, who heard voices accusing her of being a slut).

\section{Projection}

In projection, some undesirable feature of oneself is unconsciously and concretely relocated outside, as if it were never part of oneself. In 'simple' projection there is not necessarily an effect on the recipient of the projection. 
A woman, I, was regarded as a very nice person by her care coordinator and never showed any sign of aggression herself. However, she spoke frequently of the evil people in Russia that were trying to destroy everyone in the UK.

\section{Projective identification}

There are two different ways in which projective identification is used or understood. In the first way, the person projecting unwanted attributes believes that the person (or object) projected into is acting similarly with these attributes (i.e. is also projecting them back into the recipient, leading to persecution or paranoia). In the second common contemporary understanding of projective identification, the recipient often experiences something akin to what has been unconsciously projected into them. An example of this is the case of $\mathrm{J}$

\begin{abstract}
After a rejection, a young woman, J, cannot tolerate dangerous, envious, destructive feelings towards her friend, who is in a good relationship. $\mathrm{J}$ unconsciously completely reverses the situation, dressing up in expensive clothes and behaving in a variety of ways that actually arouse in the friend feelings of inadequacy, dullness and envy of J's 'freedom'. J now becomes worried that the friend's envy will have an impact on her.
\end{abstract}

\section{Splitting}

This term usually refers to separation of aspects of a person (i.e. they are not experienced together) and is often linked with denial and projection. Often, a single unwanted characteristic or a wider range of negative characteristics are 'out of the picture' the majority of the time. One common consequence is that a professional may experience a patient with psychosis as 'such a nice person' and yet the patient's auditory hallucinations might be full of vile and cruel comments and instructions. Here there is splitting and then projection of the unacceptable from self to other (as in the case of $\mathrm{E}$ ).

\section{Attacks on linking}

This describes the unconsciously motivated severance of mental connections (Bion 1959).

$\mathrm{K}$ insists that there have been no difficulties or traumas in her life that could possibly have contributed to her becoming ill. Only incidentally does she mention that her mother had had a brain tumour, and only on further prompting reveals that this happened shortly before her own illness.

\section{Fragmentation}

The feeling that things are falling apart can be experienced as a mental or physical phenomenon.

L, who always carries a knife, unexpectedly found herself in a room with a rival whom she feared would win the attention of a man she was attached to. She had the concrete experience of her arms coming off her body and saw them disappearing into 'space'.

In the integrated state (arms attached), L had had the motivation and capacity to use the knife.

\section{The manic defence}

In the manic defence, difficult-to-bear feelings of smallness, inadequacy, low self-esteem and shame are commonly unconsciously turned into the opposite, leading to the feeling of superiority, contempt, grandiosity and/or having special powers or attractiveness. See the examples relating to A (the man who was making love with a famous woman even though she was in another country) and B (the older man who believed he could function physically like a younger man).

\section{Thought disorder}

Psychotic thought disorder can be psychodynamically determined, leading to the breaking up of language and thought that would otherwise have led to ideas with painful or dangerous consequences.

\begin{abstract}
A woman, M, longed to but was unable to have children. She spent a long weekend with a married couple and their young child. The next day she was withdrawn and rapidly deteriorated, speaking in a way that an experienced practitioner could make no sense of, particularly when asked about the weekend and children, although she was able to talk about other issues in a much more ordinary way. Plenty of evidence accrued that the unconscious motivation was to make no sense (non-sense) of the weekend.
\end{abstract}

\section{Psychotic symptoms carry meaning}

It follows from the above that the psychodynamic view is that the content of psychotic symptoms is meaningful. It is important for all psychiatrists to attempt to elucidate the hidden meanings. This will be especially useful in better identifying stressors and considering interventions to minimise psychotic relapses. However, unravelling the individual's experiences and internal life may not be easy, as the psychotic processes themselves may inhibit the individual's attempts to reflect on the meaning. Nevertheless, hallucinatory experiences and delusional ideas will contain clues to both the defensive processes in play and to the underlying realities being evaded, as in the following example.

$\mathrm{N}$ came from a family where achievement was highly valued, but obtained a poor degree and in his first job was made redundant after a few months. When he became psychotic, he heard voices saying that he was useless and incompetent and others reassuring him that he was doing the right thing working on his computer on an important mission for the American government. 


\section{The stress-vulnerability model}

\section{Vulnerability}

In keeping with the original stress-vulnerability model (Zubin 1977), a psychodynamic view of psychosis acknowledges both constitutional and non-constitutional aspects of vulnerability (many of which will also confer vulnerability to other mental health problems) (Box 2). This contrasts with the view of some mental health practitioners who think of vulnerability to psychosis as purely biological, and regard symptoms consequent on personal experiences as not being 'real' psychosis.

The psychodynamic model is compatible with the possibility of genetic and other biological contributions to vulnerability, including those from biological changes consequent on life events and experiences. There is evidence now that people who develop psychosis are more likely to have experienced trauma (Read 2008), to have developed insecure styles of attachment and problems in mentalising (Gumley 2010; Lysaker 2010) and to have increased sensitivity to stress independently of neurodevelopmental factors (Myin-Gerneys 2007). Two books - Psychoses: An Integrative Perspective (Cullberg 2006) and Neuropsychoanalysis in Practice: Brain, Self and Objects (Northoff 2011) - offer sophisticated integrative approaches containing contemporary understandings of brain, neurochemistry and psychodynamic psychology in psychosis.

\section{Capacity for containment}

The capacity to bear and process affects develops within attachment relationships as part of the development of the inner world. The capacity to mentalise is an important aspect of this.

O's father had left when she was a toddler. O's mother had been depressed through most of her childhood, and often preoccupied with her own concerns. O developed an insecure-avoidant attachment style and had a sense of the world as a rather unreliable place with no one available to help her with her own anxiety. When at age 9 she was abused by a babysitter, $\mathrm{O}$ was unable not only to seek help from her mother, but also to process the experience in her own mind. In her teens, O developed hallucinations in which her abuser taunted her, and associated delusional ideas about the abuser's continuing presence.

Limitations in capacity for containment may sometimes be identified in habitual patterns of defence. In patients with a history of mania, it is common to find that, even when euthymic, they have difficulty with smaller doses of the unbearable affects that in larger doses provoked the mania.

The previously mentioned childless patient (M) who was experiencing thought disorder after spending a
BOX 2 Development of psychosis: a psychodynamic account using the stress-vulnerability model

- In early attachment relationships an individual develops an inner world which includes schemas of themselves and others and how relationships work. This inner world affects their capacity to bear, reflect on and integrate painful mental experience.

- A person's vulnerability to psychosis, i.e. their sensitivity to particular life stresses, results from their evolving emotional capacities interacting with biological factors such as neurodevelopmental features or substance use.

- The impact of life stresses depends both on vulnerability and the meaning for the individual of the particular stressors encountered. This meaning is affected by prior life experiences.

- Psychosis develops when current stresses outstrip the mind's capacity to cope through non-psychotic mechanisms.

weekend with another couple and their child, was now clinically well but could not ever feel sadness. She said that this would inevitably lead to her feeling stuck down in a deep well (with no way out).

\section{Stability of the sense of self and other}

A continuing tendency to project unacceptable aspects of the self will leave one vulnerable if exposed to excessive 'doses' of the unacceptable, when the projection defence is undermined in some way.

$P$ could never accept that in certain ways he was less able than his twin brother, and would always try to reverse the situation by trying to make his brother feel inadequate. Once the brothers separated, $\mathrm{P}$ broke down in a more and more manic way, as he could not tolerate his 'ordinary' limitations and was scared that no partner would.

Certain aspects of mental life seem to be potent sources of later decompensation. The aspects of vulnerability discussed in the rest of this section concern specific areas of sensitivity.

\section{Self-criticism}

Many individuals develop a painful, excessively self-critical aspect to their personality (a harsh superego) which can contribute to the development of later problems (including psychosis), and probably partially explains some experiences of being looked at and criticised.

Q could never satisfy his father who had high expectations of $\mathrm{Q}$ to make up for his own limited achievements. When $\mathrm{Q}$ became psychotic, he lived a dissolute life with no conscious expectations or self-observations of his own, but believed he was 
being hounded by the Prime Minister and others who were sending him demands, and that he was receiving belittling messages from the television, radio and mobile telephones, which he would smash when he could not stand their 'comments' any further.

\section{Separation and individuation}

Achieving a separate identity is a multistaged achievement built on many earlier foundation steps and consolidations. Some individuals with psychosis break down when struggling to achieve a separate sexual identity, with the disentangling of the physical and emotional attachment to one or both of their parents. Others may have experienced sexual abuse that seriously complicates this development. Actual separation from home is a further major challenge.

$\mathrm{R}$ had led a quiet adolescence becoming manifestly disturbed after she met her first boyfriend. She was fearful and guilty at any sexual touching. In her psychotic solution, she believed she was the Virgin Mary, mother of Jesus, and could save the world. Her very strict stepmother had heavily reprimanded her as a 4-year-old for attempting to touch her cousin's penis out of curiosity.

\section{Aggression}

Psychosis not infrequently seems to develop in the context of powerful feelings of aggression, and of inadequate non-psychotic strategies for managing these. See the example of D (the young man who became psychotic after his girlfriend threatened to leave if he used violence).

\section{Triangular relationships}

Difficulties with the potent issues of gender, selfesteem and rivalry are encountered in triangular situations (starting with the Oedipal constellation) and constantly revived in friendships, work and intimate relationships. They are a frequent contributor to later psychotic decompensation.

$\mathrm{S}$ was close to and possessive of her sister and had always been somewhat envious if the sister formed other important relationships. When her sister married, S broke down with delusions that her new brother-in-law was sending her secret love messages via the radio.

\section{Cultural influences}

Vulnerabilities of the types mentioned develop in response to an individual's constitution and their family and other experiences. The wider cultural context may tend to foster particular patterns of relating or of psychological defence.

The example of $\mathrm{D}$, the macho violent young man, illustrates two ways in which culture may interact with individual psychodynamics. In the earlier stages of the lives of certain young men, their cultural environment supports the development of relationships where violence is encouraged and is felt to be relatively unproblematic. When the cultural context changes, there may be a very stressful misfit between their inner and outer world, contributing to psychotic breakdown.

\section{Stress}

Just as individuals are vulnerable in specific ways, so the stresses that threaten to overwhelm will also differ. In other words, whether a particular life event has the potential to contribute to the development of psychosis (or other psychiatric problems) will depend on its significance for that individual within their inner world. On a day-today basis, whether symptoms are exacerbated by a particular experience, interaction, conversation or train of thought will depend on their meaning for the individual.

$\mathrm{N}$ recovered and remained well throughout the distressing terminal illness and death of his mother, only to relapse again when a new boss started to be critical of his work and suggested that he was underperforming.

A particular experience may be stressful either because it increases inner sources of insecurity and anxiety and arouses unwelcome affects, or because it interferes with defences that have protected against these. For N, criticism by his boss heightened his anxieties about being inferior and unlovable, and at the same time undermined his defensive strategy of meeting his own high standards of performance.

As previously mentioned, understanding the personal stressors that particularly affect an individual will assist relapse prevention.

For $\mathrm{N}$, his relapse prevention plan identified high-risk situations (e.g. when he felt his work performance was disappointing). The plan identified ways in which this specific vulnerability might be addressed, including work with the family, that helped open more compassionate conversations about expectations of each other. Later on, $\mathrm{N}$ engaged in a therapy that focused on him becoming more aware of and less at the mercy of a self-disparaging aspect of himself.

\section{Interpersonal dynamics}

\section{Psychotic and non-psychotic aspects of a person's functioning}

The extent to which the mind resorts to psychotic ways of coping varies from person to person and from moment to moment. An individual may be using reality-oriented integrating processes in some areas of their functioning and interactions, and psychotic solutions in others, even within the same conversation (Lucas 2009). 
$\mathrm{T}$, an elderly patient, was becoming very infirm and believed that people were breaking in through cracks in her floorboards to steal her (minimal) possessions. She went to complain, not to the police station, but to her doctor.

\section{Transference and countertransference}

Transference is the human tendency to distort current relationships in line with unconscious internal models of either a wished-for relationship (positive transference) or a feared relationship (negative transference), these internal models having themselves been shaped by the person's earlier relationships. These distortions have conscious and unconscious aspects. In psychosis, there may be three dimensions to an interaction, often present at the same time:

1 a rational part of the individual who understands the role of the other person and recognises their personal qualities reasonably accurately;

2 a 'neurotic' transference, where the distortion has an 'as if' rather than a concrete quality;

3 a psychotic transference where distortions of the other are experienced concretely.

$\mathrm{U}$ believed that people were spying on him and he carried a knife for self-defence. A nurse saw him at home regularly in a supportive capacity. $\mathrm{He}$ seemed to appreciate the visits and to accept that he needed his fortnightly depot injection and noticed some benefit (probable rational relationship). In their discussions there would be some hesitancies which he could overcome and could readily see were related to worries about what the nurse was thinking about him. He could understand that these linked with his self-esteem and with his experience that his parents favoured him less than his sisters (neurotic transference). He then suddenly disengaged and refused his depot medication. It became clear that in parallel to the above two dimensions he had, out of the nurse's awareness also developed an increasing conviction that she was in league with the pharmaceutical company arranging for his injection to be replaced with poison (psychotic transference).

Transference happens in all relationships, with individuals, groups and organisations. Countertransference, which is similarly ubiquitous, refers to the feelings and relationships evoked in response to transference (Bateman 1995; Hughes 2000). Consequently, transference and countertransference partially shape the relationships that patients have with the professionals working with them (Kanter 1988; Hughes 2000) and that these practitioners have with their patients and colleagues. Although often unnoticed, these phenomena are highly relevant to outcomes, whatever the practitioner's theoretical framework and whatever the treatment, whether medication, cognitive-behavioural therapy or in-patient care.
Recognising them can also provide insights into the patient's inner world and their relationships with friends and family.

Attending to transference and countertransference may elucidate meaningful understanding of important clinical challenges. For example, large numbers of patients with psychosis do not readily maintain contact with mental health professionals (Nosé 2003), and it is easy to dismiss this as the patient being unmotivated or not prepared to take responsibility. However, if one takes seriously the frequency of projection of unbearable feelings in psychosis, then this implies an alternative way of thinking about the non-engagement. The non-engagement could be understood as a 'sane' response to the patient experiencing the professional as disturbed or disturbing, as in the case of U. Developing a capacity to be open to these possibilities and to tolerate psychotic transference projections will allow staff to avoid a vicious cycle of forcing these projections back on patients who cannot yet tolerate the idea that they themselves are disturbed or lack motivation. It is then important that staff can tolerate this as an 'idea'.

Another common example is for practitioners to reduce the frequency of contact with a patient because they do not feel the patient is identifying any particular problems to work on. In some cases, careful exploration may lead to the understanding that this withdrawal has resulted from countertransference responses, where practitioners have become identified with the patient's withdrawal from disturbing aspects of what change would involve and the dangers of closeness to another person.

In contrast to withdrawal, other kinds of countertransference feelings may also provoke excessive and counterproductive interventions.

$\mathrm{V}$ emerged from a psychosis developing a progressively less abrasive relationship with his occupational therapist as his bricklaying apprenticeship proceeded and he could see himself becoming employed in some months' time. He completed his course, but then found there were no jobs. He became increasingly contemptuous of his occupational therapist, accusing her in an arrogant manner of being useless and doing nothing for him. In trying to avoid her own feelings of uselessness, which she had not recognised as countertransference, the occupational therapist tried harder and harder but the patient's disparagement only increased. The occupational therapist was helped by a psychodynamically trained colleague to bear the patient's contempt for the uselessness that he had projected onto her. She then had less need of her own 'manic' overactivity with $\mathrm{V}$, which was aimed at avoiding the painful feelings of uselessness. The occupational therapist's feeling of uselessness was a combination of a massive projection from the patient as well as a piece of external reality that she 'was' useless in not being able to find the patient a job. The 
situation became particularly problematic because of the occupational therapist's own difficulty tolerating the 'useless' feelings that affected her professional and personal self-esteem.

\section{Psychodynamics, interpersonal processes and the family}

Considering family psychodynamics is a sensitive issue because of concerns about blame and guilt. Understanding the sometimes complex dynamics of blame and guilt in psychosis may allow professionals to better engage with patient and family members, and assist with the often stressful interpersonal processes involved.

Sometimes, the vulnerability of the patient is in an area that the whole family find difficult. For example, they may all struggle to have the confidence to develop separate, relatively autonomous identities because of envy and jealousy between family members. The parents in their own adolescence may have had similar anxieties to the patient. Sometimes a single unbearable affect in the whole family seems to be crucial to determining the psychosis.

\begin{abstract}
$\mathrm{W}$, a single woman, became pregnant to a man from a very different cultural background from her own and became 'stuck' in a serious psychotic state with preoccupations about an alien. It was only when a family meeting was held that the collective avoidance of the overwhelming shame of the circumstances of the pregnancy was noticed. Skilled help for the family in tolerating and integrating this distressing affect connected with the 'alien' led to no further need for the psychotic solutions of denying and evacuating the 'alien', and the family began to be able to focus attention on the forthcoming baby.
\end{abstract}

Guilt is commonly poorly understood by professionals and seen as an affect to be assuaged. The importance of reparative guilt is overlooked. Many family members can feel uncomfortably aware that things have gone wrong in some way in the family and are concerned about the effect on the individual with psychosis. These family members are often well motivated to be of assistance. Their guilt or concern is healthy and to be welcomed and needs channelling in a constructive way. Less constructive are forms of guilt in which a family member will torment themselves in a way that is of little use to either themselves or the person with psychosis. Particularly painful to witness is when a family member is unable to feel any guilt for harm they may have done, but constantly blames and criticises (and definitely harms) the most vulnerable member of the family with the psychosis, and often also criticises the services that try to support them. This domestic situation is associated with a high risk of relapse.
It is an example of high expressed emotion - the psychodynamics of this has been considered by Migone (1995). For a fuller discussion of guilt and clinical examples see Martindale (2008).

\section{Conclusions}

In summary, we suggest the following core psychodynamic concepts in psychosis.

- Psychotic symptoms often function as a defence against unbearable aspects of reality.

- Psychotic symptoms will contain meaningful personal information disguised to varying extents, including elements of both the avoided reality and the processes by which the patient's mind has changed this.

- Psychodynamic principles offer ways of thinking about the non-constitutional aspects of vulnerability to psychosis.

- The stresses that precipitate or perpetuate psychosis may depend on the particular individual's inner world, which shapes the meaning of life experiences and the person's response to them.

- Understanding transferences and countertransferences can be helpful in making sense of interpersonal relationships for all patients with psychosis, and especially relationships between patients and staff.

- Psychodynamic approaches may also be helpful in understanding the experience of families.

\section{Acknowledgements}

We are grateful to Bent Rosenbaum, Judith Smith, Nanda Palanichamy, Jo Gorry and Ian Palfrey for thoughtful comments on earlier drafts of this article.

\section{References}

Bateman A, Holmes J (1995) Transference and countertransference. In Introduction to Psychoanalysis: Contemporary Theory and Practice, 95-117. Routledge.

Bion W (1959) Attacks on linking. International Journal of PsychoAnalysis 40: 308.

Cullberg J (2006) Psychoses: An Integrative Perspective. Routledge.

Eliot TS (1935) Burnt Norton. In Four Quartets. Faber.

*Garfield D, Mackler D (eds) (2009) Beyond Medication: Therapeutic Engagement and the Recovery from Psychosis. Routledge.

Gumley A (2010) The developmental roots of compromised mentalization in complex mental health disturbances of adulthood. In Metacognition and Severe Adult Mental Disorders: From Research to Treatment (eds G Dimaggio, PH Lysaker): 45-62. Routledge.

*Hingley S (2006) Finding meaning within psychosis: the contribution of psychodynamic theory and practice. In Evolving Psychosis: Different Stages, Different Treatments (eds JO Johannessen, BV Martindale, J Cullberg): 200-14. Routledge.

Hughes P, Kerr I (2000) Transference and countertransference in communication between doctor and patient. Advances in Psychiatric Treatment 6: 57-64. 
*Jackson M, Williams P (1994) Unimaginable Storms: A Search for Meaning in Psychosis. Karnac Books.

Kanter JS (1988) Clinical issues in the case management relationship. In Clinical Case Management: New Directions for Mental Health Services (No. 40) (eds Y Harru, LL Bachrach): 15-27. Jossey-Bass.

*Lotterman A (1996) Specific Techniques for the Psychotherapy of Schizophrenic Patients. International Universities Press.

Lucas R (2009) The Psychotic Wavelength: A Psychoanalytic Perspective for Psychiatry. Routledge.

Lysaker PH, Buck KD (2010) Metacognitive capacity as a focus of individual psychotherapy in schizophrenia. In Metacognition and Severe Adult Mental Disorders: From Research to Treatment leds G Dimaggio, PH Lyskaker): 217-32. Routledge.

Martindale B (2008) The rehabilitation of psychoanalysis and the family in psychosis: recovery from blaming. In Psychotherapies for the Psychoses (eds J Gleeson, E Killackey, H Krestev): 35-51. Routledge.

Migone P (1995) Expressed emotion and projective identification: a bridge between psychiatric and psychoanalytic concepts? Contemporary Psychoanalysis 31: 617-40.

Myin-Germeys I, van Os J (2007) Stress reactivity in psychosis: evidence for an affective pathway to psychosis. Clinical Psychology Review 27 : 409-24.
National Institute for Health and Clinical Excellence (2009) Schizophrenia: Core Interventions in the Treatment and Management of Schizophrenia in Adults in Primary and Secondary Care (Updated edition): 314. British Psychological Society and The Royal College of Psychiatrists.

Northoff G (2011) Neuropsychoanalysis in Practice: Brain, Self and Objects. Oxford University Press.

Nosé M, Barbue C, Tansella M (2003) How often do patients with psychosis fail to adhere to treatment programmes? A systematic review. Psychological Medicine 33: 1149-60.

Read J, Fink P, Rudegeair T, et al (2008) Child maltreatment and psychosis: a return to a genuinely integrated bio-psycho-social model. Clinical Schizophrenia and Related Psychoses 7: 235-54.

Summers A, Martindale B (2013) Using psychodynamic principles in formulation in everyday practice. Advances in Psychiatric Treatment, in press.

*Thorgaard LRB (2006) Schizophrenia: pathogenesis and therapy. In Evolving Psychosis: Different Stages, Different Treatments (eds J0 Johannessen, BV Martindale, J Cullberg): 64-78. Routledge.

Zubin J, Spring B (1977) Vulnerability: a new view on schizophrenia. Journal of Abnormal Psychology 86: 103-26.

${ }^{*}$ An asterisk indicates further reading containing more detailed case examples of people with psychosis.

\section{MCQs}

Select the single best option for each question stem

\section{In the psychodynamic view of the} unconscious in psychosis:

a only external reality is changed

b the mind does not try to rid itself of painful aspects

c thought disorder is always organically determined

$d$ the stress-vulnerability model is not relevant

e hypomania can be a defence against depression.

\section{The following is not a psychological} mechanism associated with psychosis:

a projection

b projective identification

c sublimation

d denial

e disavowal.
3 Which of the following statements is true:

a psychodynamics can contribute to understanding the content of psychosis but not the form

b rational relationships, neurotic and psychotic transferences can exist towards the same person alongside one another

c it is important to assuage all guilt in family members

$d$ in psychosis, failure to sustain engagement cannot be related to transference

e psychodynamic explanations of psychosis are incompatible with genetic explanations.

\section{The following may contribute to} vulnerability to psychosis:

a genetic factors

b interpersonal factors during development

c insecure attachment

d previous trauma

e all of the above.
5 Which statement is false:

a expressed emotion has been considered from a psychodynamic perspective

b searching for the hidden meaning of psychotic symptoms may assist relapse prevention

c guilt can sometimes be a useful emotion in families where there is psychosis

d a psychodynamic perspective of some psychoses is that a new reality has been created to bypass a too painful reality

e if a patient is symptom free, practitioners should necessarily reduce their contact. 